\title{
Effects of alpha-mangostin on the expression of anti-inflammatory genes in U937 cells
}

Szu-Hsiu Liu' ${ }^{1}$ Lain-Tze Lee ${ }^{1,5^{*}}$, Nai-Yun Hu' ${ }^{1}$, Kuo-Kuei Huange ${ }^{1}$, Ying-Chu Shih', linuma Munekazu², Jen-Ming Li ${ }^{3}$, Ting-Yu Chou ${ }^{3}$, Wei-Hsin Wang ${ }^{3}$ and Ting-Shou Chen ${ }^{4}$

\begin{abstract}
Background: a-Mangostin ( $\mathrm{a}-\mathrm{MG}$ ) is a main constituent of the fruit hull of the mangosteen. Previous studies have shown that a-MG has pharmacological activities such as antioxidant, antitumor, anti-inflammatory, antiallergic, antibacterial, antifungal and antiviral effects. This study aims to investigate the anti-inflammatory molecular action of a-MG on gene expression profiles.

Methods: U937 and EL4 cells were treated with different concentrations of a-MG in the presence of $0.1 \mathrm{ng} / \mathrm{mL}$ lipopolysaccharide (LPS) for $4 \mathrm{~h}$. The anti-inflammatory effects of a-MG were measured by the levels of tumor necrosis factor (TNF)-a and interleukin (IL)-4 in cell culture media, which were determined with enzyme-linked immunosorbent assay kits. The gene expression profiles of all samples were analyzed with a whole human genome microarray, Illumina BeadChip WG-6 version 3, containing 48804 probes. The protein levels were determined by Western blotting analyses.

Results: $a-M G$ decreased the LPS induction of the inflammatory cytokines TNF-a $(P=0.038)$ and IL-4 $(P=0.04)$. $a-M G$ decreased the gene expressions in oncostatin $M$ signaling via mitogen-activated protein kinase (MAPK) pathways, including extracellular signal-regulated kinases $(P=0.016)$, $c$-Jun $N$-terminal kinase $(P=0.01)$, and p38 $(P=0.008)$. a-MG treatment of U937 cells reduced the phosphorylation of MAPK kinase 3 / MAPK kinase 6 $(P=0.0441)$, MAPK-activated protein kinase-2 $(P=0.0453)$, signal transducers and activators of transcription-1 (STAT1) $(P=0.0012)$, $c-F o s(P=0.04)$, $C$-Jun $(P=0.019)$ and Ets-like molecule 1 (Elk-1) $(P=0.038)$.
\end{abstract}

Conclusion: This study demonstrates that a-MG attenuates LPS-mediated activation of MAPK, STAT1, c-Fos, c-Jun and EIK-1, inhibiting TNF-a and IL-4 production in U937 cells.

\section{Background}

The mangosteen fruit has been used in Chinese and Ayurvedic medicine [1]. Extracts of mangosteen have antioxidant, antitumor, anti-inflammatory, antiallergic, antibacterial, antifungal and antiviral effects [1-3]. $\alpha$ Mangostin $(\alpha-M G)$, which was first isolated from the mangosteen in 1855, is a competitive antagonist of the histamine $\mathrm{H}_{1}$ receptor and possesses many biological properties, such as anti-inflammatory, anti-oxidative damage and antioxidant activities [4-6]. Previous studies have shown that $\alpha-M G$ significantly inhibits nitric oxide

\footnotetext{
* Correspondence: ens@itri.org.tw

'Herbal Medicinal Product Technology Division Pharmacognosy Laboratory, Industrial Technology Research Institute, Hsinchu 30011, Taiwan

${ }^{5}$ Industrial Technology Research Institute, $321 \mathrm{Sec} .2$, Kuang Fu Road, Hsinchu 30011, Taiwan

Full list of author information is available at the end of the article
}

(NO), prostaglandin E2 (PGE2), tumor necrosis factor (TNF) $-\alpha$ and inducible NOS (iNOS) production in lipopolysaccharide (LPS)-stimulated RAW 264.7 cells [3,6,7]. PGE2, TNF- $\alpha$ and iNOS are cytokines involved in inflammatory processes, including increased vascular permeability, vascular dilation and neutrophil chemotaxis $[8,9]$.

LPS stimulation of human monocytes activates several intracellular signaling pathways that include the IкB kinase (IKK) and nuclear factor- $\mathrm{kB}$ (NF- $\mathrm{kB}$ ) pathway and three mitogen-activated protein kinase (MAPK) pathways: extracellular signal-regulated kinases 1 and 2 (ERK1/2), c-Jun N-terminal kinase (JNK) and p38 [10]. In turn, these signaling pathways activate a variety of transcription factors including NF- $\mathrm{kB}(\mathrm{p} 50 / \mathrm{p} 65)$ and activator protein 1 (AP-1; c-Fos/c-Jun), which coordinate the induction of many genes encoding inflammatory mediators [10]. However, the anti-inflammatory molecular effects of the $\alpha$-MG 
action remains unclear. Exposure of U937 cells, a human myeloid leukemic cell line, to different concentrations of $\alpha-\mathrm{MG}$ allows examination of the transcriptional responses and investigation of the exact intracellular effects of $\alpha-M G$ using complementary DNA (cDNA) microarrays.

This study aims to investigate the effects of the $\alpha-M G$ on the expression of three MAPK pathways, ERK1/2, JNK and p38 in cultured U937 cells.

\section{Methods}

\section{Chemicals and reagents}

LPS (from Escherichia coli), RPMI 1640 medium, 3-(4,5dimethyl-2-thiazolyl)-2,5-diphenyl-2 H-tetrazolium bromide (MTT), phosphate-buffered saline (PBS), antibiotics, L-glutamine and trypsin-EDTA were purchased from Gibco BRL (USA). Fetal bovine serum was purchased from Hyclone Laboratories Inc. (USA). Enzyme-linked immunosorbent assay (ELISA) test kits for Human IL-4 DuoSet and Human TNF- $\alpha$ DuoSet were obtained from R\&D Systems (USA). Phospho-p38 MAPK (Thr180/ Tyr182) rabbit monoclonal, phospho-SAPK/JNK (Thr183/ Tyr185) rabbit monoclonal, phospho-ERK1/2 (Thr202/ Tyr204) rabbit monoclonal, phospho- EIK-1 (Ser383) rabbit monoclonal, phospho-c-Fos (Ser32) rabbit monoclonal, phospho-c-Jun (Ser63) rabbit monoclonal, phospho-MMK3/MMK6 (Ser189/207) rabbit monoclonal, phospho-MAPKAPK-2 (Thr334) rabbit monoclonal, phospho-STAT1 (Try701) rabbit monoclonal, c-Fos rabbit monoclonal and c-Jun rabbit monoclonal antibodies were obtained from Cell Signaling Technology (USA). $\alpha-M G$ was provided by Dr. Iinuma Munekazu. A Bradford assay kit was purchased from Bio-Rad (Germany). A mirVana miRNA Isolation Kit was purchased from Ambion Inc. (USA). All other chemicals were purchased from SigmaAldrich (USA).

\section{Cell culture}

The human myeloid leukemic cell line U937 (ATCC No. CRL-1593.2) was purchased from the American Type Culture Collection (USA). The cells were cultured in RPMI 1640 medium supplemented with 10\% (v/v) fetal bovine serum, $2 \mathrm{mM}$ glutamine, $100 \mathrm{U} / \mathrm{mL}$ penicillin and $100 \mu \mathrm{g} / \mathrm{mL}$ streptomycin at $37^{\circ} \mathrm{C}$ under $5 \% \mathrm{CO}_{2}$. EL4 cells were purchased from the American Type Culture Collection (ATCC TIB-39). The cells were cultured in Dulbecco's modified Eagle's medium supplemented with $10 \%(\mathrm{v} / \mathrm{v})$ fetal bovine serum, $2 \mathrm{mM}$ glutamine, 100 $\mathrm{U} / \mathrm{mL}$ penicillin and $100 \mu \mathrm{g} / \mathrm{mL}$ streptomycin at $37^{\circ} \mathrm{C}$ under $5 \% \mathrm{CO}_{2}$.

\section{Differentiation induction}

U937 cells were cultured in RPMI 1640 medium supplemented with $10 \%(\mathrm{v} / \mathrm{v})$ fetal calf serum, $2 \mathrm{mM}$ glutamine, $100 \mathrm{U} / \mathrm{mL}$ penicillin and $100 \mu \mathrm{g} / \mathrm{mL}$ streptomycin at $37^{\circ} \mathrm{C}$ under $5 \% \mathrm{CO}_{2}$. For differentiation induction, the cells were seeded at a density of $2 \times 10^{7}$ cells per T150 flask. Differentiation was initiated by addition of phorbol-12-myristate-13-acetate to the culture medium to a final concentration of $50 \mathrm{ng} / \mathrm{mL}$ and allowed to proceed for $24 \mathrm{~h}$. The U937 cells were then washed with complete culture media once and incubated in U937 culture medium for $48 \mathrm{~h}$.

\section{TNF- $\alpha$ and IL-4 cytokine assays}

Differentiated U937 and EL-4 cells were aliquoted into the wells of 96-well plates at a density of $1.6 \times 10^{5}$ cells/ well, mixed with different concentrations of $\alpha$-MG. U937 cells were treated with 7.6, 12.5, $30.5 \mathrm{nM}$, respectively. EL-4 cells were treated with $3.0,6.1,12.2 \mathrm{nM}$, respectively and incubated for $30 \mathrm{~min}$ at $37^{\circ} \mathrm{C}$ under $5 \%$ $\mathrm{CO}_{2}$. LPS $(0.1 \mathrm{ng} / \mathrm{mL})$ was added to the differentiated U937 and EL-4 cells and incubated for $4 \mathrm{~h}$. The culture media were then harvested for TNF- $\alpha$ analyses with Human TNF- $\alpha$ DuoSet ELISA kit (R\&D Systems, USA). The culture media were harvested for IL-4 analyses with Human IL-4 DuoSet ELISA kit (R\&D Systems, USA). The half maximal inhibitory concentration $\left(\mathrm{IC}_{50} ; \mu \mathrm{g} / \mathrm{mL}\right)$ was calculated with GraFit software (version 7; GraFit Data Analysis Software, USA).

\section{Cytotoxicity assay}

Cytotoxicity assays were performed by the MTT method. Cells were incubated with $100 \mu \mathrm{L}$ of $1 \mathrm{mg} / \mathrm{mL}$ MTT for $1 \mathrm{~h}$ at $37^{\circ} \mathrm{C}$ under $5 \% \mathrm{CO}_{2}$. DMSO $(100 \mu \mathrm{L})$ was added to dissolve the crystals and the $\mathrm{OD}_{560}$ was measured with an ELISA reader (Spectrafluor Plus, Tecan, Switzerland). The results were expressed as cell viability percentages among LPS-stimulated cells.

\section{Microarray analysis \\ RNA isolation}

U937 cells were harvested into pellets, washed with PBS and stored at $-80^{\circ} \mathrm{C}$ until extraction. Total RNA and small RNAs from the cultured cells were isolated using the mirVana miRNA Isolation Kit.

\section{Gene expression}

The gene expression profiles were analyzed using a whole human genome microarray containing 48,804 probes (BeadChip WG-6 version 3; Illumina Inc., USA). Biotinlabeled complementary RNA (cRNA) for hybridization was generated by in vitro transcription based on the Eberwine protocol using Illumina Human Whole Genome-6 expression BeadChip kits (Illumina Inc, USA). Total RNA (500 ng) was reverse-transcribed into cDNA, followed by linear amplification steps according to an Illumina TotalPrep RNA Amplification Kit (Ambion Inc., USA). Hybridization was performed with 
$1.5 \mu \mathrm{g}$ of biotin-labeled cRNA in each BeadChip WG-6 array. After incubation at $58^{\circ} \mathrm{C}$ for $16 \mathrm{~h}$, the BeadChip WG-6 was washed with fresh wash tray according to Illumina Whohle-Genome Gene Expression Direct Hybridization Assay, stained with streptavidin-Cy3 dye (Amersham Biosciences, Buckinghamshire, UK) and scanned as described in the Illumina manual. The HumanWG-6 v3.0 Expression BeadChip WG-6 contains six arrays on a single BeadChip WG-6, each with 48,804 probes derived from human genes in the NCBI RefSeq and UniGene databases. Each array on the BeadChip WG-6 covers genome-wide transcription of well-characterized genes, gene candidates and splice variants. The intensity of each probe was calculated as the average intensity of at least 15 beads. Array images and data output were processed using Illumina BeadStudio software (Ambion Inc, USA). The analysis methods for the gene expressions using $\mathrm{R}$ and BioConductor 2.10 Software Packages (Biobase, beadarray, limma packages of R/BioConductor were used).

\section{Gene expression profiling}

The gene expression profiles of undifferentiated and differentiated U937 cells were determined using the Illumina WG-6 version 3 Beadarray (Illumina Inc., USA). The raw intensity of spots was log-2 transformed for

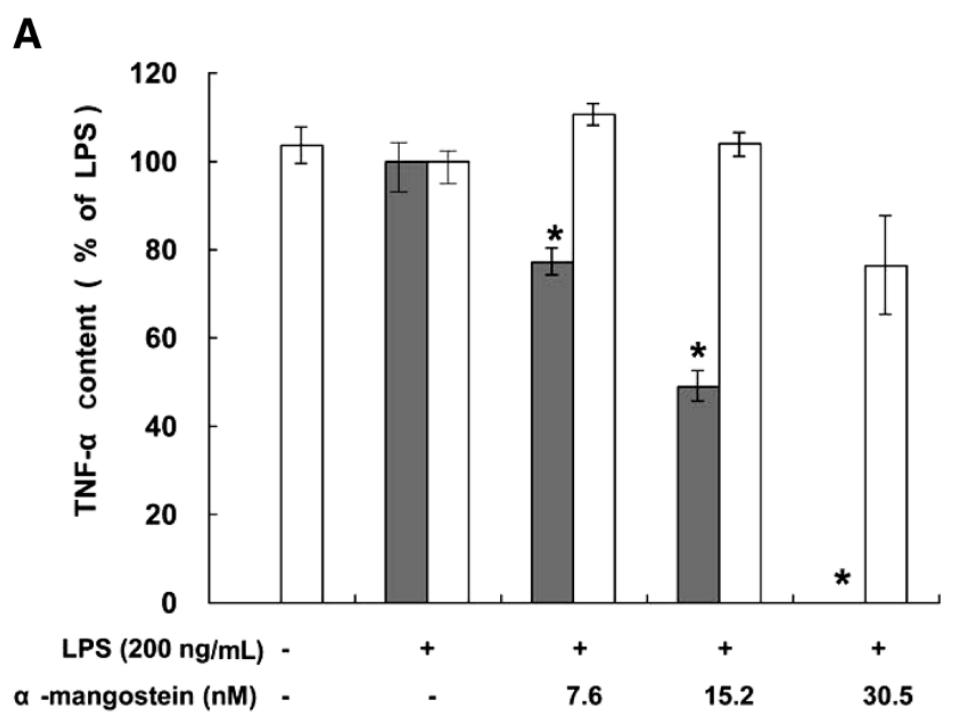

B

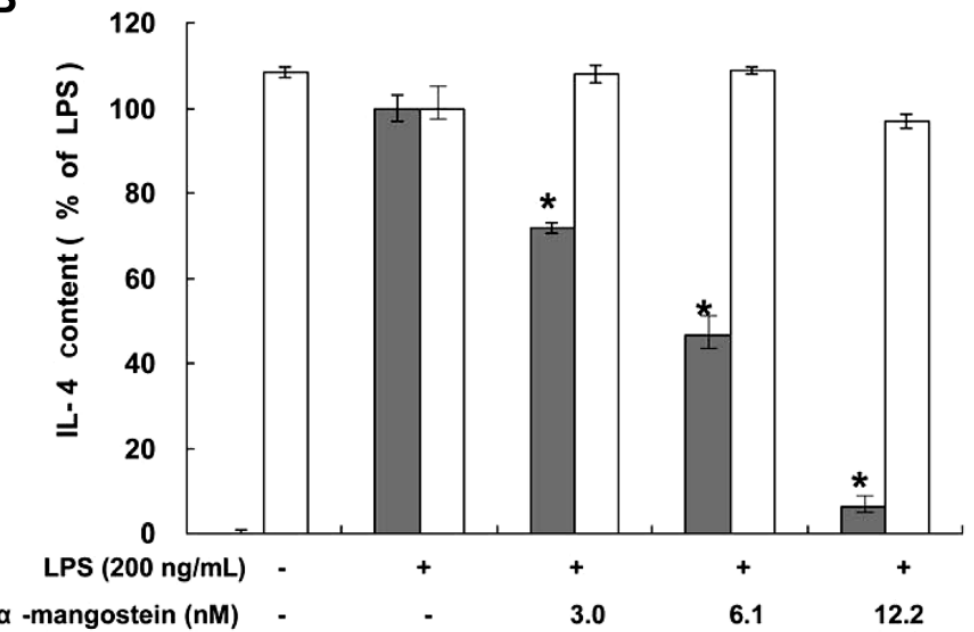

Figure 1 Inhibition of TNF- $\alpha$ and IL-4 secretion from U937 and EL4 cells by a-MG. (A) U937 cells were treated with $0.1 \mathrm{ng} / \mathrm{mL}$ LPS in the presence or absence of different concentrations of a-MG, 7.6, 12.5, $30.5 \mathrm{nM}$, respectively for $4 \mathrm{~h}$. TNF-a secreted into the conditioned media was quantified by ELISA. The TNF-a content (gray bars) and cell viabilities (open bars) are shown. (B) EL4 cells were treated with $0.1 \mathrm{ng} / \mathrm{mL}$ LPS in the presence or absence of different concentrations of a-MG, 3.0, 6.1, $12.2 \mathrm{nM}$, respectively for $18 \mathrm{~h}$. IL-4 secreted into the conditioned media was quantified by ELISA. The IL-4 content (gray bars) and cell viabilities (open bars) are shown. All experiments were performed in triplicate and repeated independently three times. ${ }^{*} P<0.05$, significant difference from LPS treatment. 
subsequent analysis. Quantile normalization was performed within all arrays to adjust the systematic variation of experiments and dye effects. Significantly changed genes were identified by Limma test with $\mathrm{BH}$ (Benjamini \& Hochberg) adjust $P$ values of less than 0.05 .
Pathway and gene ontology analysis

The pathway and gene ontology analyses were performed using the MetaCore software (GeneGo Inc., USA), in which the differentially expressed gene sets for LPS and $\alpha$-MG comprised the significantly changed genes between the two conditions and were annotated

A
\begin{tabular}{|l|c|c|}
\hline Name & P value & Network objects \\
\hline Immune response_IL-1 signaling pathway & $6.67 \mathrm{E}-07$ & $7 / 44$ \\
Apoptosis and survival_TNFR1 signaling pathway & $9.65 \mathrm{E}-06$ & $6 / 43$ \\
Mucin expression in CF via IL-6, IL-17 signaling pathways & $4.28 \mathrm{E}-05$ & $5 / 34$ \\
Development_Thrombopoetin signaling via JAK-STAT pathway & $1.11 \mathrm{E}-04$ & $4 / 22$ \\
Immune response_Antiviral actions of Interferons & $3.38 \mathrm{E}-04$ & $5 / 52$ \\
Immune response_IL-6 signaling pathway & $3.39 \mathrm{E}-04$ & $4 / 29$ \\
Development_Role of HDAC and calcium/calmodulin-dependent kinase & $4.04 \mathrm{E}-04$ & $5 / 54$ \\
(CaMK) in control of skeletal myogenesis & $4.79 \mathrm{E}-04$ & $5 / 56$ \\
Immune response_TLR signaling pathways & $7.08 \mathrm{E}-04$ & $4 / 35$ \\
Immune response_Oncostatin M signaling via MAPK in mouse cells & $8.77 \mathrm{E}-04$ & $4 / 37$ \\
Immune response_Oncostatin M signaling via MAPK in human cells & $9.72 \mathrm{E}-04$ & $4 / 38$ \\
Transcription_Role of AP-1 in regulation of cellular metabolism & $1.07 \mathrm{E}-03$ & $4 / 39$ \\
Cytokine production by Th17 cells in CF & $1.18 \mathrm{E}-03$ & $4 / 40$ \\
Immune response_Th1 and Th2 cell differentiation & $1.51 \mathrm{E}-03$ & $5 / 72$ \\
Reproduction_GnRH signaling & $2.06 \mathrm{E}-03$ & $3 / 22$ \\
Immune response_MIF-mediated glucocorticoid regulation & $2.53 \mathrm{E}-03$ & $4 / 49$ \\
Immune response_Bacterial infections in normal airways & $2.53 \mathrm{E}-03$ & $4 / 49$ \\
Cytokine production by Th17 cells in CF (Mouse model) & $2.72 \mathrm{E}-03$ & $4 / 50$ \\
Immune response_Function of MEF2 in T lymphocytes & $2.93 \mathrm{E}-03$ & $4 / 51$ \\
Mucin expression in CF via TLRs, EGFR signaling pathways & $3.37 \mathrm{E}-03$ & $4 / 53$ \\
Apoptosis and survival_Endoplasmic reticulum stress response pathway & \\
\hline
\end{tabular}

B

\begin{tabular}{|c|c|c|c|c|c|c|}
\hline \multirow[t]{2}{*}{ Gene group } & \multicolumn{6}{|c|}{ Gene name or symbol } \\
\hline & \multicolumn{3}{|c|}{ Down-regulation } & \multicolumn{3}{|c|}{ Up-regulation } \\
\hline $\begin{array}{l}\text { Inflammatory } \\
\text { response }\end{array}$ & $\begin{array}{l}\text { HMOX1 } \\
\text { MGLL } \\
\text { IRAK2 } \\
\text { ORM1 } \\
\text { ADORA2A } \\
\text { STAT5A } \\
\text { RIPK2 } \\
\text { CXCL10 } \\
\text { TNFAIP6 } \\
\text { PTGS2 } \\
\end{array}$ & $\begin{array}{l}\text { OLR1 } \\
\text { NFKB1 } \\
\text { CCL4L1 } \\
\text { IL6 } \\
\text { IL18RAP } \\
\text { CCR7 }\end{array}$ & & $\begin{array}{l}\text { CXCR4 } \\
\text { TNFSF4 } \\
\text { RXRA } \\
\text { PROK2 } \\
\text { CYSLTR1 } \\
\text { FOS } \\
\text { C3AR1 } \\
\text { GHRL } \\
\text { ADORA3 } \\
\text { PPARG } \\
\end{array}$ & $\begin{array}{l}\text { SERPINE1 } \\
\text { ZFP36 } \\
\text { TNF } \\
\text { MMP25 } \\
\text { NFKBIZ } \\
\text { FPR2 } \\
\text { OSM } \\
\text { GBA } \\
\text { NFATC3 } \\
\text { CSF1R } \\
\end{array}$ & $\begin{array}{l}\text { IL10RB } \\
\text { DUSP10 } \\
\text { ITGAL } \\
\text { LTA4H }\end{array}$ \\
\hline $\begin{array}{l}\text { Immune } \\
\text { response }\end{array}$ & $\begin{array}{l}\text { EBI3 } \\
\text { AQP9 } \\
\text { IRAK2 } \\
\text { BCL2 } \\
\text { NFKB2 } \\
\text { CCL1 } \\
\text { RIPK2 } \\
\text { CD70 } \\
\text { IL7R } \\
\text { CXCL10 }\end{array}$ & $\begin{array}{l}\text { HERC5 } \\
\text { CCL14 } \\
\text { TANK } \\
\text { IFIH1 } \\
\text { AIM2 } \\
\text { NFKB1 } \\
\text { GBP2 } \\
\text { CCL4L1 } \\
\text { P2RX7 } \\
\text { EOMES }\end{array}$ & $\begin{array}{l}\text { L18R1 } \\
\text { TRIM25 } \\
\text { CD86 } \\
\text { OASL } \\
\text { HLA-DQA1 } \\
\text { IL6 } \\
\text { IL18RAP } \\
\text { CCR7 } \\
\text { PVR } \\
\text { ISG15 }\end{array}$ & $\begin{array}{l}\text { IL PSTPIP1 } \\
\text { CD37 } \\
\text { SIGIRR } \\
\text { PELI2 } \\
\text { MALT1 } \\
\text { LILRB2 } \\
\text { CD4 } \\
\text { SPN } \\
\text { CD1D } \\
\text { TNFSF4 FOS } \\
\text { KIR2DL4 } \\
\text { SASH3 } \\
\text { TMEM173 } \\
\text { CORO1A } \\
\text { FYB } \\
\text { PPARG } \\
\text { NFIL3 } \\
\text { UBE2L6 } \\
\text { KIR3DL2 } \\
\text { LILRA5 } \\
\text { PYCARD } \\
\text { ITGAL } \\
\text { KIR2DS5 } \\
\text { CTSC } \\
\text { IL18RAP } \\
\end{array}$ & $\begin{array}{l}\text { PTPN22 } \\
\text { FCGR2B } \\
\text { C5AR1 } \\
\text { GPR183 } \\
\text { ICAM4 } \\
\text { CD1A } \\
\text { KIR2DL3 } \\
\text { TREM2 } \\
\text { MAPKAPK3 } \\
\text { SRPK2 FCGR1B } \\
\text { IL27RA } \\
\text { EXOSC9 } \\
\text { INPP5D } \\
\text { IFITM2 } \\
\text { BTK } \\
\text { CARD9 } \\
\text { TNF } \\
\text { HLA-DMA } \\
\text { HLA-DMB } \\
\text { ITGA418R1 } \\
\text { TRIM25 } \\
\text { CD86 } \\
\text { OASL } \\
\text { HLA-DQA1 }\end{array}$ & $\begin{array}{l}\text { IL6 } \\
\text { RNF125 } \\
\text { S1PR4 } \\
\text { FCGR1A } \\
\text { OSM } \\
\text { BMI1 } \\
\text { FCAR } \\
\text { ST6GAL1 } \\
\text { WAS } \\
\text { FUT7 } \\
\text { KIR3DL1 } \\
\text { CX3CR1 } \\
\text { VEGFA } \\
\text { IFITM1 } \\
\text { JUN } \\
\text { IL10RB } \\
\text { MR1 } \\
\text { ICAM2 } \\
\text { NOTCH1 } \\
\text { KIR2DL1 } \\
\text { DUSP10 } \\
\text { CCR7 } \\
\text { PVR } \\
\text { ISG15 }\end{array}$ \\
\hline
\end{tabular}

Figure 2 Microarray analysis of a-MG in LPS-stimulated U937 cells. (A) Analysis of a-MG-regulated pathways using the MetaCore database (most significant 20 pathways). (B) Groups of genes suppressed or induced following exposure to a-MG. 


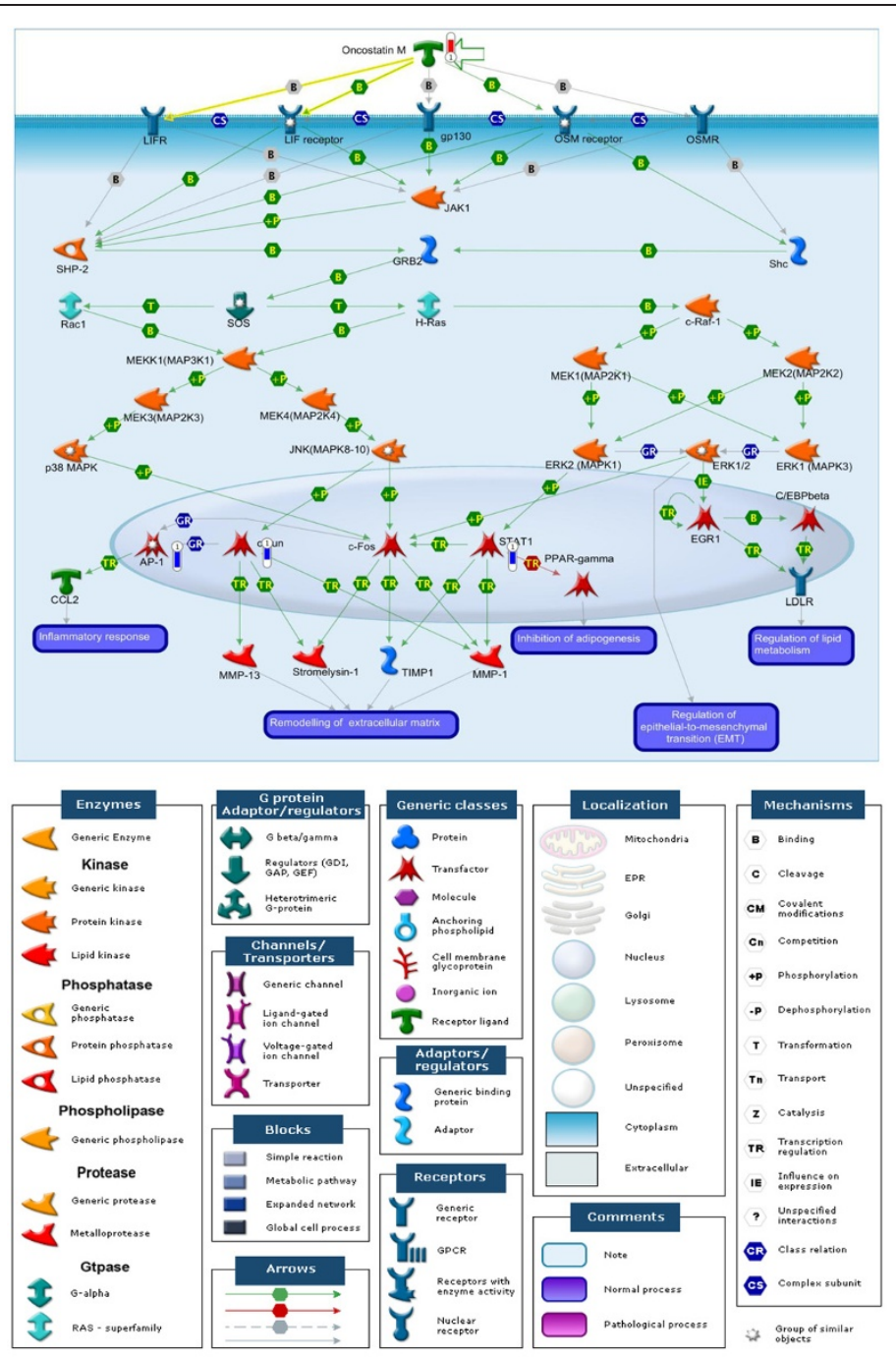

\begin{tabular}{|c|c|c|c|}
\hline Input ids & Network object name & Gene symbol & Signal (log2) \\
\hline JUNB & AP-1 & JUNB & -1.434402824 \\
JUN & C-Jun ,AP-1 & JUN & -1.092340172 \\
OSM & Oncostatin M & OSM & 1.13289427 \\
STAT1 & STAT1 & STAT1 & -1.123433941 \\
\hline
\end{tabular}


(See figure on previous page.)

Figure 3 a-Mangostin regulates OSM signaling in U937 cells. Four genes (JUNB, JUN, OSM, STAT1) are differential expressed between the LPS-alpha treated state and LPS-only treated state.

according to their biological processes based on gene ontology information.

\section{Western blot analysis}

Differentiated U937 cells at a density of $4 \times 10^{6}$ cells/well were pretreated with $13.4 \mathrm{nM} \alpha-\mathrm{MG}$ for $30 \mathrm{~min}$. The U937 culture medium contained $0.1 \mathrm{ng} / \mathrm{mL}$ LPS, and the incubation was continued for $4 \mathrm{~h}$ at $37^{\circ} \mathrm{C}$ under $5 \% \mathrm{CO}_{2}$. The cells were washed twice with ice-cold PBS, resuspended in lysis buffer (20 mM Tris- $\mathrm{HCl} \mathrm{pH} 7.5,150 \mathrm{mM} \mathrm{NaCl}$, $1 \mathrm{mM}$ EDTA, 1 mM EGTA, 1\% Triton X-100, 2.5 mM sodium pyrophosphate, $1 \mathrm{mM} \beta$-glycerophosphate, $1 \mathrm{mM}$

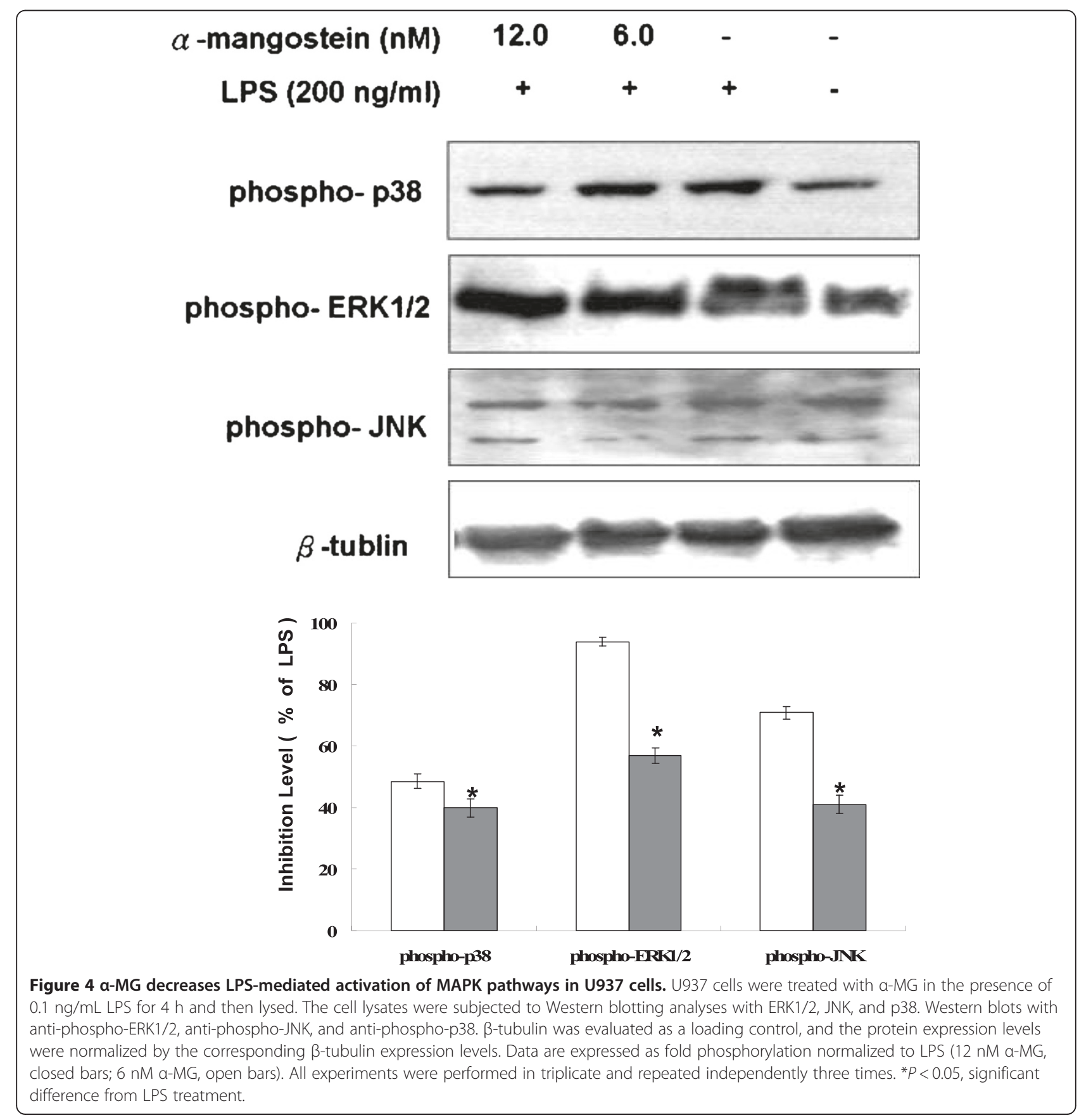


$\mathrm{Na}_{3} \mathrm{VO}_{4}, 1 \mu \mathrm{g} / \mathrm{mL}$ leupeptin, $1 \mathrm{mM}$ PMSF) and centrifuged (Thermo Fisher Scientific Laboratory, USA) at $16,000 \times g$ for $15 \mathrm{~min}$ at $4^{\circ} \mathrm{C}$. The clarified cell lysates were used for Western blot analyses. The protein concentrations were determined using the Bradford assay kit (Ambion Inc., USA).

Protein extracts $(20 \mu \mathrm{g})$ under reduced conditions were fractionated by $10 \%$ sodium dodecyl sulfatepolyacrylamide gel electrophoresis and transferred to Hybond nitrocellulose membranes. The membranes were blocked with 3\% non-fat milk in Tris-buffered saline containing $0.1 \%$ Tween for $1 \mathrm{~h}$. The activations of $\mathrm{p} 38$,
MAPK, JNK, ERK1/2, EIK-1, c-Fos, c-Jun, MAPK kinase 3 / MAPK kinase 6 (MMK3/MMK6), MAPK-activated protein kinase-2 (MAPKAPK-2) and signal transducers and activators of transcription-1 (STAT1) were assessed using phospho-p38 MAPK (Thr180/Tyr182) rabbit monoclonal, phospho-SAPK/JNK (Thr183/Tyr185) rabbit monoclonal, phospho-ERK1/2 (Thr202/Tyr204) rabbit monoclonal, phospho-EIK-1 (Ser383) rabbit monoclonal, phospho-cFos (Ser32) rabbit monoclonal, phospho-c-Jun (Ser63) rabbit monoclonal, phospho-MMK3/MMK6 (Ser189/ 207) rabbit monoclonal, phospho-MAPKAPK-2 (Thr334) rabbit monoclonal, phospho-STAT1 (Try701) rabbit

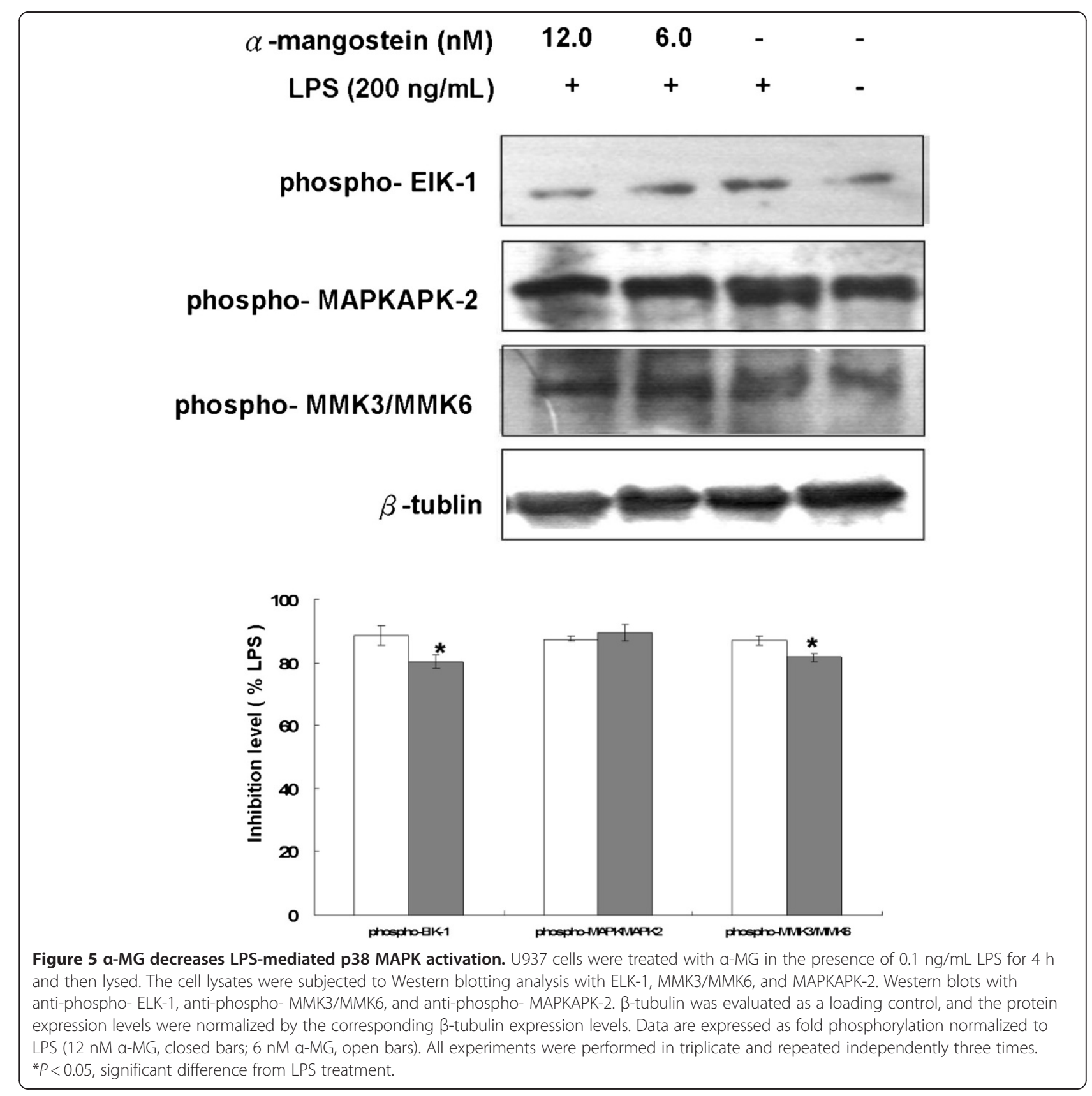




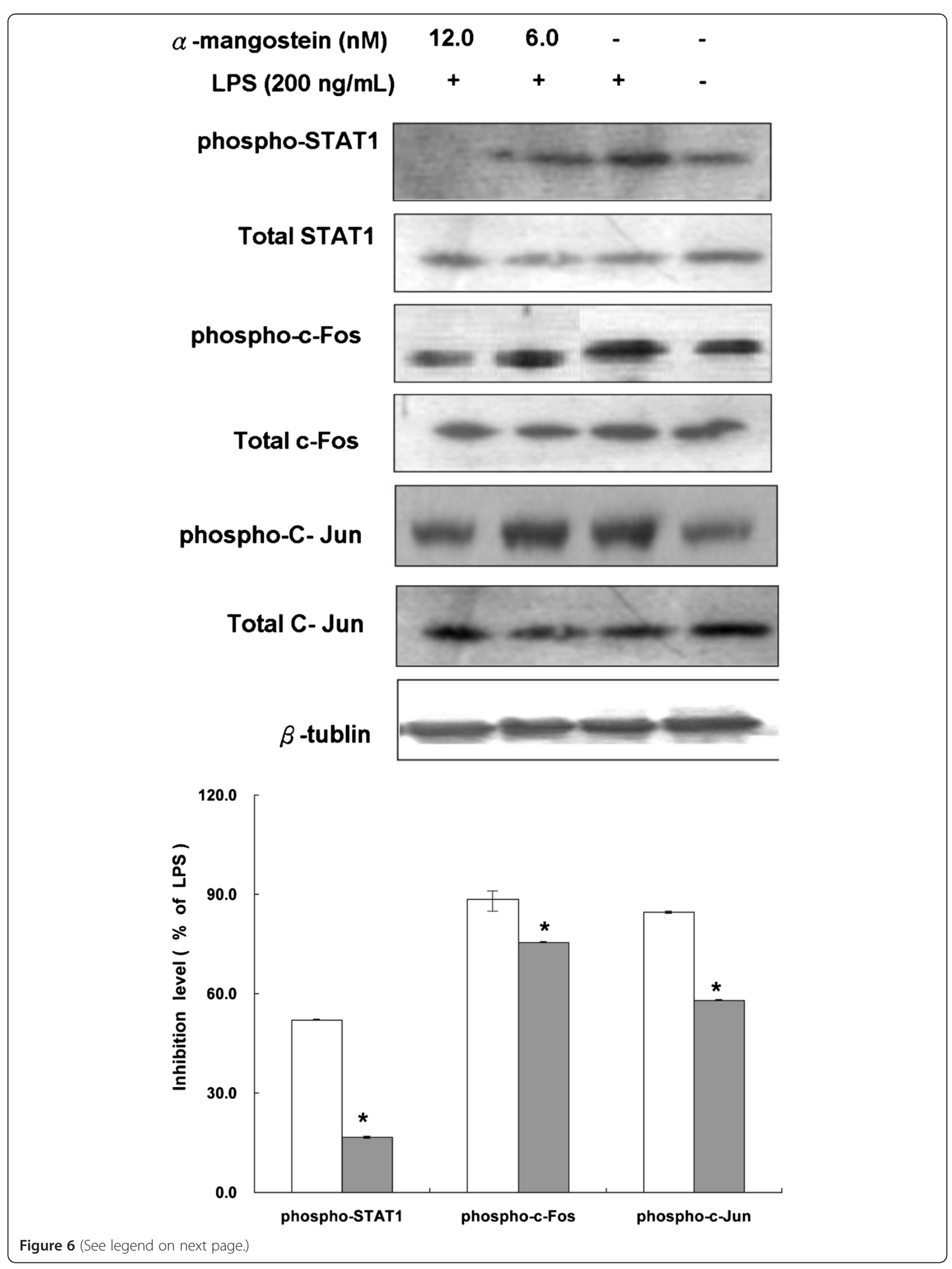


(See figure on previous page.)

Figure 6 a-MG regulates STAT 1, c-Jun and c-Fos. U937 cells were treated with a-MG in the presence of 0.1 ng/mL LPS for 4 h and then lysed. The cell lysates were subjected to Western blotting analyses with STAT 1, c-Jun, c-Fos. Western blots with anti-phospho- STAT 1, anti-phospho- c-Jun, and anti-phospho- c-Fos. $\beta$-tubulin was evaluated as a loading control, and the protein expression levels were normalized by the corresponding $\beta$-tubulin expression levels. Data are expressed as fold phosphorylation normalized to LPS (12 nM a-MG, closed bars; 6 nM a-MG, open bars). All experiments were performed in triplicate and repeated independently three times. ${ }^{*} P<0.05$, significant difference from LPS treatment.

monoclonal, c-Fos rabbit monoclonal and c-Jun rabbit monoclonal antibodies according to the manufacturer's instructions. The antibody-bound protein bands were visualized by incubation with a horseradish peroxidaseconjugated secondary antibody (Sigma-Aldrich, USA), followed by detection using the ECL system (Amersham Pharmacia Biotech, USA). The integrated optical densities of the bands were quantified using Image J software $(\mathrm{NIH}$, USA). Each sample was normalized by the $\beta$-tubulin content, as a constitutively expressed protein.

\section{Statistical analysis}

All experiments were performed in triplicate and repeated independently at least three times. Data were presented as mean \pm standard deviation (SD) and analyzed by one-way analysis of variance (ANOVA) using SAS 9.1.3 software (SAS Institute Inc., USA) followed by a Tukey test to determine any significant differences. $P$ values less than 0.05 were considered statistically significant. Dose dependence was visually determined from the dose-response graphs.

\section{Results and discussion}

\section{Inhibition of LPS-induced TNF- $a$ and IL-4 production}

LPS significantly induced the production of TNF- $\alpha$ and IL4 in U937 cells. The inhibitory effects of $\alpha-M G$ on inflammatory cytokines were evaluated by measuring the amounts of secreted TNF- $\alpha$ and IL-4 in LPS-stimulated U937 cells after treatment with $\alpha$-MG. $\alpha$-MG inhibited the production of TNF- $\alpha \quad(P=0.038)$ (Figure $1 \mathrm{~A})$ and IL-4 $(P=0.04)$ (Figure $1 \mathrm{~B}$ ) in a dose-dependent manner. The antiinflammatory effects of $\alpha-\mathrm{MG}$ could be attributed to the inhibition of inflammatory cytokine production or a reduction in the number of U937 cells through cytotoxicity. The latter possibility was excluded by comparing the numbers of cells cultured with the different concentrations of $\alpha-\mathrm{MG}$, wherein no significant decreases in cell viability were observed when the concentration was below $15.2 \mathrm{nM}$ $(P=0.1)$ (Figure $1 \mathrm{~A})$. The $\mathrm{IC}_{50}$ of $\alpha-\mathrm{MG}$ was $13.4 \pm 0.4 \mathrm{nM}$.

\section{Microarray analysis}

Treatment of LPS-stimulated U937 cells with $13.4 \mathrm{nM} \alpha-$ MG changed the gene expression pattern (Figure 2A). There were 1536 and 1491 significantly changed genes at 1 and $6 \mathrm{~h}$ with LPS and the combination of LPS and $\alpha$ MG, respectively. The gene expressions altered after $\alpha-$ MG treatment were involved in pathways related to inflammation-based immune responses, stress responses, regulation of apoptosis and regulation of programmed cell death. Among the approximately 183 genes showing the strongest suppression, 46 genes were related to immune responses and inflammatory responses (Figure $2 \mathrm{~B}$ ). These immune response-related pathways were involved in IL-1 signaling, oncostatin M (OSM) signaling, cytokine production, and Th1 and Th2 cell differentiation.

OSM is expressed in autoimmune diseases, including rheumatoid arthritis, multiple sclerosis and inflammatory conditions [11]. We observed that $\alpha-M G$ is a promising agent for autoimmune diseases (unpublished data). The results from the microarray showed that JUNB, c-Jun, OSM and STAT1 were differentially expressed between the LPS and $\alpha$-MG-cotreated and LPS-treated cells in the OSM pathway (Figure 3). $\alpha-M G$ may regulate OSM signaling via MAPK pathways and related downstream proteins, including STAT1, c-Jun and c-Fos. The inhibitory actions on three MAPK pathways, ERK1/2, JNK and p38, were examined to delineate the effects of $\alpha-\mathrm{MG}$.

\section{Decrease in LPS-mediated MAPK activation}

LPS treatment induced the phosphorylation of p38, ERK $1 / 2$ and JNK, and $\alpha-M G$ treatment attenuated these responses in a dose-dependent manner $(P=0.008$ for phospho-p38; $P=0.016$ for phospho-ERK1/2; $P=0.01$ for phospho-JNK) (Figure 4). The level of p38 phosphorylation was significantly decreased compare with ERK1/2 and JNK (Figure 4). $\alpha$-MG (12 nM) greatly inhibited p38 phosphorylation, and the phosphorylation was reduced to just $38 \%$ of that in LPS-treated cells.

EIK-1, MMK3/MMK6 and MAPKAPK-2 are substrates of p38 [12], and the effects of $\alpha-M G$ on their phosphorylation were also examined. LPS treatment induced phosphorylation of EIK-1 and MMK3/MMK6, and $\alpha-M G$ treatment attenuated these responses in a concentration-dependent manner $(P=0.038$ for phosphoEIK-1; $P=0.0441$ for phospho-MMK3/MMK6; $P=0.0453$ for phospho- MAPKAPK-2). EIK-1, MMK3/MMK6 and MAPKAPK-2 phosphorylation was greatly inhibited by 12 $\mathrm{nM} \alpha-\mathrm{MG}$, and the phosphorylation was reduced to just $78-82 \%$ of that in LPS-treated cells (Figure 5). These findings suggest that $\alpha$-MG exhibits anti-inflammatory activity by inhibiting MAPK phosphorylation, especially in the p38 pathway including EIK-1, MMK3/MMK6 and MAPKAPK-2. 


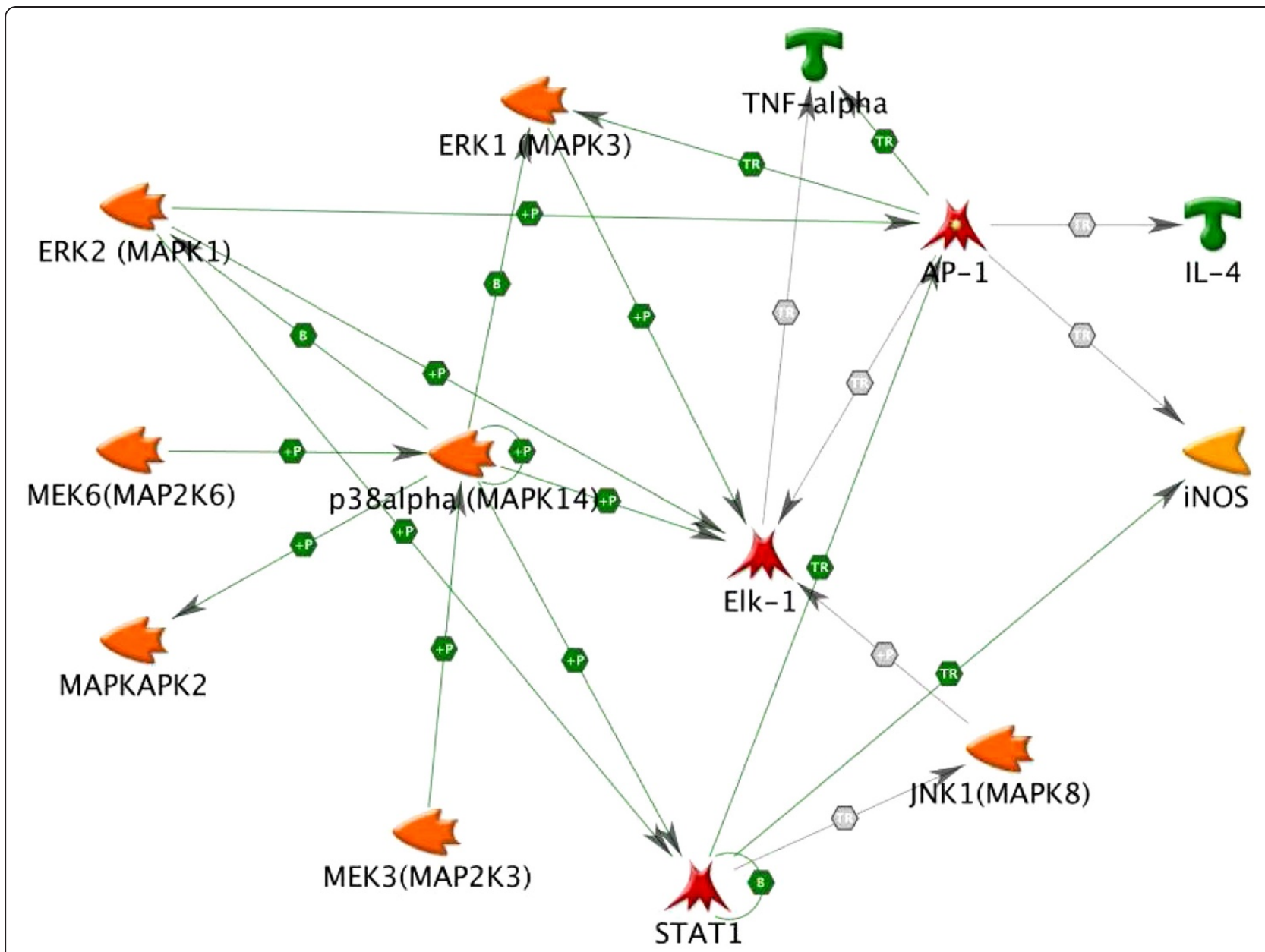

Figure 7 Pathway analysis of a-MG effects on gene expression in U937 cells.

\section{Regulation of STAT1, c-Jun and c-Fos}

The results from the microarray showed that JUNB, c-Jun, OSM and STAT1 were differentially expressed between the LPS and $\alpha$-MG-cotreated and LPS-treated cells in the OSM pathway. The protein levels of STAT1, c-Jun and cFos were determined by Western blotting analyses. Specifically, $\alpha$-MG pretreatment attenuated LPS-induced phosphorylation of c-Jun and c-Fos and downstream targets of JNK and ERK1/2 ( $P=0.04$ for phospho-c-Fos) (Figure 6). We demonstrated that $\alpha-M G$ reduced the induction of STAT1 $(P=0.0012)$, c-Jun and c-Fos in a concentrationdependent manner.

As shown in Figure 7, we have demonstrated that the anti-inflammatory effects of $\alpha$-MG involves the following: (1) attenuation of LPS-induced production of IL-4 and TNF- $\alpha$; (2) attenuation of LPS-induced activation of JNK, ERK1/2 and p38; (3) reduction of LPS-induced activation of EIK-1, MMK3/MMK6 and MAPKAPK-2; and (4) attenuation of LPS-mediated suppression of STAT1, c-Jun and c-Fos expression. Taken together, these new findings demonstrate that $\alpha-M G$ inhibits LPS-mediated activation of inflammatory AP-1, MAPK and MAPK-related proteins, including STAT1, c-Jun and c-Fos.

\section{Conclusion}

This study has demonstrated that $\alpha-M G$ attenuates LPS activation of MAPK, STAT1, c-Fos, c-Jun and EIK-1, thereby inhibiting TNF- $\alpha$ and IL-4 production in U937 cells.

\section{Abbreviations}

PMA: Phorbol-12-myristate-13-acetate; IC 50 : Half maximal inhibitory concentration; MTT: 3-(4,5-dimethyl-2-thiazolyl)-2,5-diphenyl-2 H-tetrazolium bromide; PBS: Phosphate-buffered saline; ANOVA: Analysis of variance; AP-1: Activator protein 1; JNK: c-Jun N-terminal kinase; MAPKAPK-2: Mitogen activated protein kinase-activated protein kinase-2; cDNA: Complementary DNA; cRNA: Complementary RNA; ELISA: Enzyme-linked immunosorbent assay; Elk-1: Ets-like molecule 1; ERK1/2: Extracellular signal-regulated kinases 1 and 2; IKK: IKB kinase; IL: Interleukin; iNOS: Inducible NOS:

LPS: Lipopolysaccharide; MMK3: MAPK kinase 3; MMK6: MAPK kinase 6; MAPK: Mitogen-activated protein kinase; NF-kB: Nuclear factor-kB; OSM: Oncostatin M; PGE2: Prostaglandin E2; STAT1: Signal transducers and activators of transcription-1.

\section{Competing interests}

The authors declare that they have no competing interests. 


\section{Authors' contributions}

LTL and IM designed the study. SHL performed the Western blotting and statistical analyses, and wrote the manuscript. NYH, KKH and YCS performed the cytokines assay experiments. JML, TYC, WHW and TSC performed the microarray experiments and wrote the manuscript. All authors read and approved the final manuscript.

\section{Acknowledgements}

The study was financially supported by grants from the Industrial Technology Research Institute (ITRI) (Grant Number A356EJ2100) and Gifu Pharmaceutical. University.

\section{Author details}

'Herbal Medicinal Product Technology Division Pharmacognosy Laboratory, Industrial Technology Research Institute, Hsinchu 30011, Taiwan. 'Laboratory of Pharmacognosy, Gifu Pharmaceutical University, Gifu 501-1196, Japan. ${ }^{3}$ Strategic Business \& Innovation Technology Development Division, Industrial Technology Research Institute, Hsinchu 30011, Taiwan. ${ }^{4}$ In Vitro Diagnostics Division, Industrial Technology Research Institute, Hsinchu 30011, Taiwan. ${ }^{5}$ Industrial Technology Research Institute, 321 Sec.2, Kuang Fu Road, Hsinchu 30011, Taiwan.

Received: 27 March 2012 Accepted: 14 August 2012

Published: 24 August 2012

\section{References}

1. Chen LG, Yang LL, Wang CC: Anti-inflammatory activity of mangostins from Garcinia mangostana. Food Chem Toxicol 2008, 46:688-693.

2. Pedraza-Chaverrí J, Reyes-Fermín LM, Nolasco-Amaya EG, Orozco-Ibarra M, Medina-Campos ON, González-Cuahutencos O: ROS scavenging capacity and neuroprotective effect of a-mangostin against 3-nitropropionic acid in cerebellar granule neurons. Exp Toxicol Pathol 2009, 61:491-501.

3. Chomnawang MT, Surassmo S, Nukoolkarn VS, Gritsanapan W: Effect of Garcinia mangostana on inflammation caused by Propionibacterium acnes. Fitoterapia 2007, 78:401-408.

4. likubo K, Ishikawa Y, Ando N, Umezawa K, Nishiyama S: The first direct synthesis of a-mangostin, a potent inhibitor of the acidic sphingomyelinase. Tetrahedron Lett 2002, 43:291-293.

5. Martindale J, Bland-Ward PA, Chessell IP: Inhibition of C-fibre mediated sensory transmission in the rat following intraplantar formalin. Neurosci Lett 2001, 316:33-36.

6. Tewtrakul S, Wattanapiromsakul C, Mahabusarakam W: Effects of compounds from Garcinia mangostana on inflammatory mediators in RAW264.7 macrophage cells. J Ethnopharmacol 2009, 121:379-382.

7. Chen Y, Yang L, Lee TJ: Oroxylin A inhibition of lipopolysaccharideinduced iNOS and COX-2 gene expression via suppression of nuclear factor-kB activation. Biochem Pharmacol 2000, 59:1445-1457.

8. Stichtenoth DO, Frolich JC: Nitric oxide and inflammatory joint diseases. Br J Rheumatol 1998, 37:246-257.

9. Choi EM, Hwang JK: Effects of Morus alba leaf extract on the production of nitric oxide, prostaglandin E2 and cytokines in RAW264.7 macrophages. Fitoterapia 2005, 76:608-613.

10. Guha M, Mackman N: LPS induction of gene expression in human monocytes. Cell Signal 2001, 13:85-94.

11. Repovic P, Mi K, Benveniste EN: Oncostatin M enhances the expression of prostaglandin $E_{2}$ and cyclooxygenase-2 in astrocytes: Synergy with interleukin-1 $\beta$, tumor necrosis factor- $a$, and bacterial lipopolysaccharide. GLIA 2003, 42:433-446.

12. Yong HY, Koh MS, Moon A: The p38 MAPK inhibitors for the treatment of inflammatory diseases and cancer. Expert Opin Investig Drugs 2009, 18:1893-1905.

doi:10.1186/1749-8546-7-19

Cite this article as: Liu et al:: Effects of alpha-mangostin on the expression of anti-inflammatory genes in U937 cells. Chinese Medicine 2012 7:19.

\section{Submit your next manuscript to BioMed Central and take full advantage of:}

- Convenient online submission

- Thorough peer review

- No space constraints or color figure charges

- Immediate publication on acceptance

- Inclusion in PubMed, CAS, Scopus and Google Scholar

- Research which is freely available for redistribution 